placement of the whole of the lines in the star spectrum would be measured simultaneously. He proposes to photograph the spectrum of the star, with the terrestrial comparison spectrum alongside it, as usual, and then to photograph the solar spectrum and the same comparison with the same instrument. The two negatives are then placed in a specially devised measuring machine, and the solar plate moved by the micrometer screw until the similar lines in both the solar and the stellar spectra coincide. Then the solar plate is again moved by the screw until the lines in the comparison spectrum on it coincide with the analogous lines in the comparison spectrum on the stellar spectrogram. The difference between the two settings gives the displacement of the stellar lines, from which the radial velocity is computed. In the reduction, which is simple, the only assumption made is that the lines have the same wave-lengths in the solar and the stellar spectra, and this is permissible, at least with second-type stars for which the method was primarily devised (Astrophysical Journal, vol. xx., No. 5).

\section{MEDICAL RESEARCH IN EGYPT.}

$\mathrm{A}^{\mathrm{N}}$ interval of three years has elapsed since the first volume of these "Records" was published. The present series of papers would alone afford abundant evidence of the activity of the members of the staff in the intervening period. But it is still more satisfactory to recollect that this does not represent the total output of research, for many other memoirs from the same source have already appeared elsewhere. There are evidently many problems of both local and general importance which require investigation, and the standard of excellence reached in the "Records" already published arouses a desire that succeeding volumes should appear more frequently.

The papers are naturally chiefly concerned with problems of special local importance. The three scourges of Egypt are said to be the malarial parasite, Ankylostoma and Bilharzia. The last seems to bring an extraordinary number of cases under the care of the surgical staff, some 16 per cent. of all surgical in-patients suffering directly from lesions produced by this parasite. From the pathological report by Dr. Symmers, it would appear that about 7 per cent. of the deaths are directly due to Bilharzia. In roo consecutive admissions to the medical wards, 35 were found to have the eggs in their urine, though only two of these were suffering in any way from the infection. The surgical aspects of the disease are discussed in two interesting papers by $\mathrm{Mr}$. Madden and $\mathrm{Mr}$. Milton; they find that many pathological conditions turn out most unexpectedly to be due to the worm. At one period of life or another practically the whole of the native population is said to be infected. Unfortunately, no material progress has been made in elucidating the extracorporeal history of the parasite; it is therefore impossible to take any direct preventive measures.

Dr. Phillips contributes an article on the relation of ascites to malaria. In at least one-third of the cases of ascites in Kasr-el-Ainy no cause could be found other than malaria, but the ætiological connection is not very clearly established. A definite malarial cirrhosis occurs in a certain number of the cases, but it is not always present, and the conditions found appear to be very variable.

Of ankylostomiasis there is nothing in this volume beyond incidental mention. But, as is well known, the most important recent contributions to our knowledge of this destructive world-disease have come from the Cairo Medical School. Dr. Looss, in a long series of papers, has most ably carried on the investigations begun by Griesinger in the same school fifty years ago, and we are disappointed to find here no sequel to his account of the Sclerostomidæ of horses and asses which appeared in the first volume of the "Records."

Dr. Wilson follows up his observations on the poisons of spiders by a very interesting study of the venom of Egyptian scorpions. An aqueous extract of the poison gland is treated with excess of alcohol, and from the

I "Records of the Egyptian Government School of Medicine." Vol. ii., roo4. Edited by H. B. Keatinge, M. B., Director. Pp. r6g+plates. (Cairo : National Printing Department, IgO4.) precipitate thus obtained a substance may be extracted with normal saline which possesses toxic properties of a very high order. The toxic value is about ten million, that is, I milligram will kill ro kilograms of guinea-pig - a figure of the same order as that obtained for similar preparations from the venoms of the more poisonous serpents. A full-grown specimen of the common Egyptian species (Buthus quinque-striatus) contains about $3 \frac{1}{2}$ milligrams of this (impure) "toxin." If the susceptibility of man is the same as that of the laboratory animals, it follows that a single sting can kill at the utmost 35 kilograms. These calculations correspond very well with the fact that fatal cases of scorpion sting in adults are extremely rare, though the mortality in young children reaches 60 per cent. Scorpions are in this way on a different level from many of the poisonous snakes; as Captain Lamb has shown, the amount of toxin normally injected by a vigorous cobra is many times the minimum lethal dose for an adult man. Dr. Wilson finds that certain animals living in the desert (including the hedgehog) are naturally immune (at any rate relatively) to the venom; and Dr. Tallart has immunised goats and obtained an anti-toxic serum with curative properties.

An article by Dr. Tribe shows that phthisis in Egypt does not differ very much in frequency, incidence on rural and urban populations, and type from the same disease in western Europe; and Dr. Sobhy gives a curious account of the obstetric customs of the natives, which seem to have undergone no material change since very remote times. The volume concludes with the first instalment of what promises to be a monumental contribution to the morphology of the human brain, by Dr. Elliot Smith. The present section, which is fully illustrated, deals with the occipital region, and contains a great deal of original matter on the vexed questions of the significance and homologies of the convolutions.

The general printing of the volume is excellent, though the inevitable misprint has crept in here and there. The illustrations are good and useful, but we are sorry to see that the coloured plate illustrating Dr. Symmers's case of secondary sarcoma of brain could not be printed in Egypt. A. E. B.

\section{WIRELESS TELEGRAPHY IN WAR.}

A VERY interesting account of the working of the wireless telegraphic war correspondence of the Times during the early part of the Russo-Japanese war was given by Captain James at a meeting of the Society of Arts last week. This is the second occasion on which the Times has played a prominent and important part in the practical development of wireless telegraphy. The first was when, shortly after Mr. Marconi had established communication between America and England, a regular correspondence was started between the two countries by means of wireless telegraphy - a correspondence which was not, however, destined to last for very many days. Very soon after its inception something went wrong, and though since that time the Marconi Company has greatly developed its Transatlantic signalling and has effectively demonstrated its utility and convenience for communicating with liners, the shore to shore correspondence has not been renewed.

The second case in which the Times intervened was also only of short duration; but here the cessation was due to its having met with too great success, the results achieved having demonstrated not that wireless telegraphy is useful for war correspondence, but that it is too effective to be permissible.

The system selected for the equipment of the Haimun was that of Dr. de Forest, a system which had already shown its efficiency during the yacht races of 1903 ; the reasons that led to the choice of this system were its freedom from interference and the speed at which it could be worked, it being possible to transmit thirty to thirtyfive words a minute, as against ten to twelve words by any other system. The experiences of Captain James seem certainly to bear out the claim of freedom from interference. In spite of the fact that four other systems were at work in close proximity to the Haimun-the 